\title{
Brincar e Contar Histórias com Crianças com Transtorno do Espectro Autista: MediaÇão do Adulto ${ }^{1}$ Playing and Telling Stories with Children with Autism Spectrum DisORDER: MEDIATION OF ADULTS
}

\author{
Débora DELIBERATO² \\ Fernanda Delai Lucas ADURENS ${ }^{3}$ \\ Aila Narene Dahwache Criado ROCHA ${ }^{4}$
}

\begin{abstract}
RESUMO: O objetivo deste estudo foi descrever a mediação do adulto e as habilidades comunicativas de duas crianças com Transtorno do Espectro Autista, em situaçóes lúdicas, por meio da narração de histórias. As atividades foram realizadas em um Centro Especializado em Reabilitação de uma cidade do interior do estado de Sáo Paulo. Foram selecionadas duas crianças do gênero masculino com 2 anos e 9 meses e 3 anos e 3 meses de idade. Os dados foram coletados durante seis meses, por meio de atividades semanais com as famílias e profissionais da saúde, seguindo um programa de intervenção com histórias. As atividades foram filmadas e registradas por meio do diário de campo. As categorias e as subcategorias foram identificadas após a transcrição dos vídeos e incorporação dos registros do diário de campo em um texto único organizado em sequência temporal das atividades. As categorias e as subcategorias identificadas em relaçáo aos objetivos deste estudo foram: a) mediação do adulto: modelação, questionamento e entonação da voz do adulto interlocutor, uso de sistemas suplementares e alternativos de comunicação: sistema tangível, sistema pictográfico e mediação combinada; b) habilidades de expressão: expressão verbal e vocal, expressão não verbal e vocal, expressão não verbal e não vocal, expressões combinadas. Os resultados ilustraram a importância da mediação do adulto na atividade da narração de histórias como um instrumento para o acesso à linguagem e às habilidades comunicativas das crianças envolvidas durante o processo de mediação.
\end{abstract}

PALAVRAS-CHAVE: Educação Especial. Mediação da linguagem. Narração de histórias. Educação Infantil. Comunicação Alternativa.

ABSTRACT: The aim of this study was to describe the mediation of adults and the communication skills of two children with Autism Spectrum Disorder, in playful situations, through storytelling. The activities were carried out in a Specialized Rehabilitation Center in a city in the hinterlands of the state of Sáo Paulo, Brazil. Two male children aged 2 years and 9 months and 3 years and 3 months old were selected. Data were collected during six months, through weekly activities with families and health professionals, following an intervention program with stories. The activities were filmed and recorded through the field diary. The categories and subcategories were identified after the videos were transcribed and the field diary records were incorporated into a single text organized in time sequence of the activities. The categories and subcategories identified in relation to the objectives of this study were: a) adult mediation: modeling, questioning and intonation of the adult interlocutor's voice, use of supplementary and alternative communication systems: tangible system, pictographic system and combined mediation; b) skills of expression: verbal and vocal expression, non-verbal and vocal expression, non-verbal and non-vocal expression, combined expressions. The results illustrated the importance of adult mediation in the activity of storytelling as an instrument for accessing language and communicative skills of the children involved during the mediation process.

KEYWORDS: Special Education. Language mediation. Storytelling. Early Childhood Education. Alternative Communication.

\footnotetext{
${ }^{\mathrm{I}}$ https://doi.org/10.1590/1980-54702021v27e0128

${ }^{2}$ Universidade Estadual Paulista "Júlio de Mesquita Filho". Faculdade de Filosofia e Ciências. Marília/São Paulo/Brasil. E-mail: debora.deliberato@unesp.br ORCID: https://orcid.org/0000-0003-4756-042X

${ }^{3}$ Universidade Estadual Paulista "Júlio de Mesquita Filho". Faculdade de Filosofia e Ciências. Marília/São Paulo/Brasil. E-mail: fernandadla10@gmail.com. ORCID: https://orcid.org/0000-0002-4741-5532

${ }^{4}$ Universidade Estadual Paulista "Júlio de Mesquita Filho". Faculdade de Filosofia e Ciências. Marília/São Paulo/Brasil. E-mail: aila.rocha@unesp.br. ORCID: https://orcid.org/0000-0001-6186-875X
} 


\section{INTRODUÇÁo}

O brincar é a atividade por excelência das crianças; ocupa papel central na vida delas, sendo objeto de estudo de inúmeros pesquisadores (Scalha et al., 2010). É por meio das diferentes maneiras de brincar, considerando a idade, que as crianças desenvolvem as habilidades motoras, sensoriais, cognitivas, socioafetivas, contando com a mediaçáo dos adultos ou a interação entre os pares (Vitta et al., 2017). Ademais, a brincadeira, quando é mediada por adultos, pode resultar em maior socializaçáo e diminuição de comportamentos negativos e inadequados das crianças nesses momentos de interação (Trivellato-Ferreira et al., 2016).

Nos casos de crianças com Transtorno do Espectro Autista (TEA), o brincar mediado pode ser um importante facilitador para interação social (Martins \& Góes, 2013) e configura-se como meio de comunicação (Mattos \& Nuernberg, 2011). Para isso, fazem-se necessárias mediaçóes específicas para a interação, considerando a singularidade de cada criança, suas necessidades e potencialidades (Mattos \& Nuernberg, 2011).

O estudo de Menezes e Amorim (2015) investigou a interaçáo social de crianças com diagnóstico de TEA no contexto familiar. As autoras analisaram os processos de atenção conjunta. Os resultados mostraram que, mesmo com a presença de estereotipias e comportamentos repetitivos, foram identificados recursos comunicativos na interação e o estabelecimento de atenção conjunta e de negociaçôes de interesses, que partiram das crianças com TEA.

Assim sendo, interlocutores e mediadores como a família, os profissionais e/ou professores podem exercer funçóes importantes no desenvolvimento e no enriquecimento da linguagem e da comunicação das crianças com TEA, de modo a contribuir com a interação social. Ademais, os interlocutores envolvidos no trabalho de mediação são fundamentais para que se estabeleça uma comunicação (Light et al., 2019). McNaughton et al. (2019), por meio de um estudo de meta análise, discutiram a importância e a necessidade do interlocutor com competência na mediaçấo centrada nas habilidades e nas necessidades das pessoas com necessidades complexas de comunicação, para favorecer o enriquecimento da interação e da comunicação dessas pessoas.

As crianças brincam e constroem narrativas, por meio da mediação e da interação com o meio que as circunda (Cruz et al., 2017), e a participação delas em atividades de narração de histórias pode favorecer a ampliação do vocabulário, assim como propiciar a vivência no contexto cultural do idioma da sua comunidade (Deliberato \& Adurens, 2019; Deliberato \& Ferreira-Donati, 2020).

A narração de histórias é uma atividade que faz parte da rotina familiar desde a tenra idade dos filhos, bem como do contexto escolar, principalmente na Educação Infantil, fase fundamental para o enriquecimento da linguagem. Pode ocorrer nos diálogos, por meio de relatos pessoais até a elaboração das histórias de ficção (Oliveira \& Scherer Júnior, 2019; Perroni, 1992; Smith, 2015). Campos (2016) realizou oficinas de criação de história a fim de compreender as narrativas de crianças acerca de suas experiências, e a influência dessa prática na formação delas. Dentre os resultados, verificou-se que a narração de histórias promoveu a criaçáo de laços e o compartilhamento de experiências.

Nas situaçōes lúdicas com as histórias, a criança com TEA pode manifestar habilidades de interação e de comunicação não percebidas pelo interlocutor. A literatura tem discutido 
a importância de olhar e aceitar as diferentes manifestaçóes de comunicação em função da diversidade de habilidades de cada pessoa com TEA. A intencionalidade de uma comunicação pode dar-se por meio de inúmeras manifestaçóes e não somente por meio da fala, tais como: choro, gestos, olhar, expressão corporal, entre outras possibilidades. Tais habilidades são de suma importância, embora seja necessário um sistema de representação compartilhado no meio social, para que as pessoas possam trocar informaçóes e expressar-se de forma mais efetiva (Tomasello, 2003).

Nesse contexto de discussão, pesquisadores alertaram a necessidade da inserção da área da Comunicação Suplementar e Alternativa de forma precoce para as crianças com TEA (Nunes \& Walter, 2017). O uso dos sistemas pictográficos e tangíveis na rotina de atividades funcionais permeia a construção de um sistema simbólico compartilhado. As atividades do brincar, narração de histórias são recursos e estratégias enriquecedoras nesse processo de constituição de um sistema de representação, principalmente quando a fala não se desenvolve (Solomon-Rice \& Soto, 2011). Nessa perspectiva, a interlocução entre a família, a escola e os profissionais de saúde são fundamentais (Rocha, 2013). Ambos devem assumir o compromisso de acompanhar o desenvolvimento infantil, inclusive viabilizar a comunicação (Binger \& Light, 2007).-

Há poucos estudos a respeito de programas de intervenção que discutem recursos e estratégias que atuam com a narração em crianças e jovens com TEA para a estimulação da linguagem, comunicação e interação em uma perspectiva colaborativa. O ensino de estratégias na construção de histórias feitas por profissionais da saúde, que atuam de forma colaborativa com os professores e a família, poderá permitir a mediação no suporte para novos interlocutores que atuam com a rotina da criança como TEA, como, no caso, os professores da Educação Infantil (Mendes et al., 2011).

Perante as questóes introduzidas, este estudo teve como objetivo descrever a mediação do adulto e as habilidades comunicativas de crianças com TEA em situaçôes lúdicas, por meio da narração de histórias.

\section{Método}

O presente estudo descritivo e de natureza qualitativa foi avaliado e aprovado pelo Comitê de Ética em Pesquisa. As atividades foram desenvolvidas em um Centro Especializado em Reabilitação, localizado em uma cidade do interior do estado de Sáo Paulo, em um programa que oferece atendimento nas áreas da Saúde e Educação.

Foram selecionadas duas crianças do gênero masculino com TEA: a Criança C1: com 2 anos e 9 meses; e a Criança C2: com 3 anos e 3 meses. Ambas as crianças frequentavam a escola de Educação Infantil no próprio município e não tinham desenvolvido a fala como instrumento de comunicação. As crianças iniciaram a intervenção no Centro Especializado em Reabilitação nas áreas de terapia ocupacional, fonoaudiologia e psicologia no início de 2018.

Os dados foram coletados durante seis meses no ano de 2018, por meio de sessóes semanais com duração de uma hora, em salas de atividades direcionadas para atividades lúdicas e contação de histórias. As atividades foram selecionadas e programadas com participação das famílias das crianças e dos profissionais envolvidos (uma psicóloga, uma terapeuta ocupacional 
e uma fonoaudióloga). Assim sendo, inicialmente foi realizado com as mães o preenchimento do protocolo de habilidades comunicativas (Delagracia et al., 2015) com o objetivo de identificar a rotina de atividades e de interesse das crianças selecionadas, assim como as habilidades comunicativas já utilizadas e observadas pelas mães e professoras (Paula et al., 2015).

Após a identificação dos brinquedos preferidos pelas crianças e temas de histórias desenvolvidos nas escolas, as profissionais da saúde elaboraram o programa de atividades de narração de histórias, baseado na proposta de Ponsoni (2010). O programa foi dividido em momentos: o primeiro momento foi a exploração dos personagens das histórias selecionadas; o segundo momento foi o desenvolvimento de atividades em relação ao local da ação; e, por fim, o terceiro momento foi a vivência com a ação propriamente dita do enredo da história. Nesse contexto, a atividade do brincar foi inserida na sequência temporal da narração. Foram selecionados os seguintes temas de histórias para análise deste estudo: "Carros" e "Os três porquinhos", "Senhora Batata" e a "História de vida". Os critérios de seleção dos temas foram: interesse das crianças e envolvimento do tema com a escola. Após a seleção dos temas, as histórias foram adaptadas por meio dos sistemas suplementares e alternativos de comunicação, seguindo as etapas de Deliberato (2013).

Os recursos de Comunicação Suplementar e Alternativa foram utilizados para colaborar no suporte para o desenvolvimento do discurso narrativo (Hayward \& Scheneider, 2000; Mcgregor, 2000). Embora o programa tenha sido elaborado para as duas crianças selecionadas, as atividades com as duas crianças foram realizadas em dias e horários diferentes em função do momento de desenvolvimento de cada criança e disponibilidade de horários. Durante as atividades programadas, houve a participação das mães das crianças selecionadas, profissionais da saúde e outras crianças do Centro Especializado em Reabilitação. As ações foram mediadas pelos diferentes profissionais perante os objetivos do plano da atividade; desse modo, nas atividades nas quais somente um dos profissionais estava realizando uma determinada tarefa com a criança e/ou família, ele era o profissional o mediador. Já no momento que a atividade foi realizada com mais de um profissional, o mediador era aquele que oferecia o suporte mais direcionado para a tarefa, de acordo com a demanda da criança, associada à especialidade do profissional. Além da mediação feita por profissionais, a família, principalmente a mãe, também foi orientada na mediação das atividades, bem como participou do processo de elaboração e de seleção das metas. As possibilidades de mudança de mediador em uma mesma atividade foram discutidas pelo grupo no momento da elaboração do plano e após cada intervenção.

As atividades foram registradas por meio da filmagem (Carvalho, 1996) e do diário de campo. As filmagens foram transcritas e as informaçóes do diário de campo foram incorporadas no texto escrito, e todas as informaçóes foram organizadas de forma temporal da realização das atividades (Fonseca, 1999). As categorias e subcategorias foram identificadas e organizadas a partir do objeto de interesse deste estudo. As definiçóes das categorias e das subcategorias foram estabelecidas para este estudo a partir das propostas já descritas por Campelo et al. (2009) e Millikin (1997). Foram identificadas as seguintes categorias e subcategorias: 
- Categoria A - Mediação do adulto: Toda ação realizada pelos interlocutores para auxiliar as crianças durante a realização das atividades. Foram identificadas as seguintes subcategorias:

a.1 Modelação: toda instrução realizada a partir de um modelo oferecido: instrução oral e a instruçáo motora.

a.2 Questionamento: toda pergunta realizada por um interlocutor para direcionar a criança na atividade e entonação da voz: variação no tom de voz do mediador ao emitir vocalizaçóes: sílabas, palavras ou frases.

a.3 Uso de sistemas suplementares e alternativos de comunicação: quando o interlocutor usou um sistema de apoio para a comunicação. Os sistemas utilizados foram: sistema tangível: uso de objetos na interação; uso de sistema pictográfico: uso de imagens na interação; uso de medição combinada: uso de mais de uma estratégia de mediação durante a interação na atividade proposta.

- Categoria B - Habilidades de expressáo: toda possibilidade das crianças de interagir no momento das atividades propostas com intencionalidade de compartilhar com o interlocutor. Nessa categoria, foram identificadas as seguintes subcategorias:

b.1 Expressão verbal e vocal: Toda expressão utilizada pelas crianças com o uso de fonemas, sílabas ou palavras da língua natural da comunidade, podendo ser compreendida ou não pelo interlocutor, mas com uso intencional na comunicação com o outro. Nessa subcategoria, poderiam ser incluídos sistemas suplementares e alternativos de comunicação com voz sintetizada e/ou digitalizada.

b.2 Expressão não verbal e vocal: toda emissão utilizada pelas crianças durante a interação com um outro interlocutor com intenção comunicativa, mas sem o uso da emissão por meio de fonemas e/ou palavras inteligíveis: grito, choro; padrão de entonação vocal.

b.3 Expressão não verbal e não vocal: emissão utilizada pelas crianças durante a interação com um outro interlocutor por meio de gestos, expressóes faciais e outras possibilidades de comportamento com o corpo durante a interação sem a utilização de sons, mas com intenção comunicativa.

b.4 Expressóes combinadas: quando a criança utilizou mais de uma modalidade de expressão durante uma situação de interação.

As categorias e as subcategorias estabelecidas neste estudo foram avaliadas por juízes da área com os seguintes índices de concordância: Juiz A: 95,83\% e o Juiz B: 83,33\%. Segundo Fagundes (1999), índices maiores do que 70\% são considerados bons, confiáveis.

\section{Resultados E discussáo}

Os resultados serão apresentados e discutidos por meio das categorias e subcategorias identificadas para este estudo. A primeira categoria está relacionada à mediação do adulto inter- 
locutor, e a segunda categoria vincula-se às habilidades expressivas das duas crianças participantes deste estudo. A legenda utilizada nos exemplos selecionados foi: P: Pesquisadora; C1: Participante 1; C2: Participante 2; M1: mãe do participante C1; M2: mãe do participante C2, TO: Terapeuta Ocupacional; FO: Fonoaudiólogo e o símbolo $(\boldsymbol{\gamma})$ para indicar a entonação do interlocutor. Nos exemplos selecionados para as subcategorias, o conteúdo alvo está grifado em negrito.

\subsection{Mediaçáo do adulto}

Os estudos apresentados por Von Tetzchner (2015) reforçaram que a criança com necessidades complexas de comunicação, como no caso da criança com TEA, precisa de um suporte para a aquisição da linguagem, principalmente em relação a interlocutores competentes nas linguagens alternativas. Nessa mesma perspectiva, Light e McNaughton (2015) alertaram para a necessidade do uso de novas tecnologias de Comunicação Suplementar e Alternativa nos diferentes ambientes, sem perder de vista o entendimento das especificidades de cada pessoa. Assim sendo, a narração de história permitiu aos adultos oferecer o suporte ou a mediação apropriada às crianças com TEA. A seguir, os exemplos poderão ilustrar situaçóes nas quais a pesquisadora usou o modelo oral e/ou motor para a criança participar do processo de construção da história.

\subsubsection{MODELAÇÁO}

A modelação tem sido descrita pela literatura como uma estratégia importante para o ensino de novas habilidades das crianças durante o desenvolvimento de suas competências. A criança com desenvolvimento típico pode ter na sua rotina o envolvimento com interlocutores que favorecem padróes de modelos de suporte natural, que auxiliam na aquisição e no desenvolvimento da linguagem (Oliveira \& Scherer Júnior, 2019; Smith, 2015; Von Tetzchner, 2018). A imersão da criança com TEA no contexto das histórias pode favorecer a ela modelos que sejam suporte para o desenvolvimento de suas competências, como pode ser observado a partir do Exemplo 1 descrito a seguir:

Exemplo 1: participantes: pesquisadora P e a criança 1: C1. Atividade: construção da casa de madeira do porquinho (telhado). O Exemplo 1 descreve a pesquisadora utilizando modelo oral e modelo por meio da ação motora durante a elaboração do local da ação da história narrativa (casa do porquinho) que estava sendo desenvolvida:

P: Pega uma cola e passa em um quadrado de EVA e diz para C1: "Oh, vem aqui pertinho".

C1: Vem em direção à $P$ e observa o que $P$ está fazendo. Pega um quadrado de EVA da máo de $\mathrm{P}$ e coloca em cima da mesa e pega outro quadrado de EVA para passar em cima do que estava com cola.

P: Coloca lá no telhado. Ah! Você vai fazer assim. P observa C1 colocar um quadrado sobre o outro em cima da mesa. Opa. Grudou!

C1: Joga o quadrado de EVA em direção a casa.

P: Pega um quadrado de EVA e coloca no telhado da casa, dizendo: "olha aqui oh. Olha aqui onde eu vou colocar. Colei aí. Está colado".

C1: Pega um quadrado e coloca no telhado. 
O envolvimento da criança com TEA neste perfil de estratégia facilita a participação sensorial e perceptiva com o material selecionado, qual seja, o vocabulário necessário para a elaboração da narrativa. Nesse momento, o uso de objetos no contexto da história pode permitir às crianças com TEA a participação de forma a vivenciar o vocabulário durante sua ação sensorial, perceptiva e motora.

Esses achados estão em consonância com os resultados de Fiorini (2017). A pesquisadora descreveu a rotina de sete crianças com TEA da Educação Infantil e observou que a participação dessas crianças na atividade de contos e recontos de histórias estava permeada em relação a dois aspectos: o primeiro aos recursos concretos e por meio de imagens que a professora deixava disponível; e o outro à mediação utilizada com o aluno, para favorecer sua participação.

Outro aspecto apontado por Perroni (1992), durante o desenvolvimento da narrativa em relação à participação do interlocutor, foi o uso de perguntas realizadas à criança, como, por exemplo: "Onde? Como? O quê?". A autora também alertou para o uso de elementos que propiciam o vínculo entre a sequência dos fatos, como o uso: "e daî", "e então", "e depois".

Neste estudo, a mediação da pesquisadora com perguntas foi definida como questionamento. A pergunta ainda poderia estar associada à entonação vocal do mediador. A prosódia da língua de uma comunidade é uma característica importante do desenvolvimento da linguagem infantil, como já discutida anteriormente. Ela pode oferecer às crianças com TEA o modelo de uso nas situaçóes de comunicação.

\subsubsection{QUESTIONAMENTO E ENTONAÇÁO DE VOZ}

Os exemplos 2 e 3 ilustram as mediaçóes realizadas pelo pesquisador com a criança C2 e C1 em relação à estratégia de questionamento e da entonação de voz utilizada durante as atividades com as crianças.

No Exemplo 2, a pesquisadora e a terapeuta ocupacional observam as açóes motoras realizadas pela criança com TEA ao movimentar com as mãos dois pinguins em miniatura e fazem perguntas a ela, com o intuito de nomear, significar a respectiva ação.

Exemplo 2: Participantes: pesquisadora: P, terapeuta ocupacional: TO e a criança 2: C2. Atividade: livro sobre animais e as miniaturas correspondente (sistema tangível).

C2: Está sentado na cadeira apoiando dois pinguins em cima da mesa um de frente para o outro e os movimenta.

TO: Você está colocando os pinguins para conversar?

C2: Olha rapidamente para TO, junta os dois pinguins em uma mão só e levanta essa mão para cima, olha para máo que está levantada e balança a mão, faz um movimento no ar.

TO: Eles vão voar, agora?

C2: Abaixa as mãos.

Quanto ao Exemplo 3, a pesquisadora deu ênfase em determinadas sílabas e palavras de um fragmento da história no qual a criança demonstrava maior interesse, como o momento em que o lobo cai no caldeirão. 
Exemplo 3: participantes: pesquisadora: P e criança 1: C1. Atividade: história dos três porquinhos por meio da leitura de texto interativo e a construção das casas dos personagens.

P: É essa casinha do porco que a gente vai construir hoje, o lobo mau vai entrar aqui no caldeirão "ai, ai, ai, ai, ai, meu bumbum” , “aiłăi, ai, ai, ai, meu bumbum”.

C1: Pegaso lobo do livro interativo e coloca no caldeirão

P: “ai al ai lobo, cuidado" $\Rightarrow$ Tibum. Caiu. 'ai, ai, ai, socorro"

C1: Virava as páginas do livro e olhava as imagens

P: "ai, ai, ai, socorro"

Por meio dos Exemplos 2 e 3, é possível observar que a estratégia da narração de histórias permitiu aos parceiros de comunicação interação com as crianças, envolvendo a manutenção da troca dialógica. A mediação no contexto dialógico na narração permitiu suporte para as estruturas iniciais que permitiram habilidade expressiva, mas também deu condiçóes para o modelo entonacional no contexto da estrutura da língua. A fala com diferentes entonaçóes pode favorecer a atenção direcionada da criança, principalmente quando a história envolve vários personagens (Deliberato \& Ferreira-Donati, 2020).

Smith (2015), em seus estudos, descreveu a necessidade do uso precoce dos sistemas suplementares e alternativos de comunicação como apoio às diferentes situaçóes da comunicação e interação. Solomon-Rice e Soto (2011) também alertaram que a narração de histórias é um recurso que pode facilitar a inserção desses sistemas. A subcategoria sistemas suplementares e alternativos de comunicação, apresentada a seguir, implica o uso dos sistemas tangíveis (objetos), sistemas pictográficos e a escrita como possibilidades de comunicação.

\subsubsection{SistemaS SUPLEMENTARES E ALTERNATIVOS DE COMUNICAÇÃO}

O Exemplo 4 ilustra uma atividade que apresentava a experiência de vida: a rotina alimentar da criança com TEA. Diante da resistência e da seletividade alimentar da criança, foi proposto, após conversas com a mãe a respeito da rotina do filho e de suas preferências alimentares, um piquenique. Além das frutas reais, foram apresentadas as miniaturas de frutas (objetos) e as imagens de cada uma delas, como pode ser observado a seguir.

Exemplo 4: participantes: pesquisadora: P, fonoaudiólogo: FO e criança 2: C2. Atividade: história de vida da criança: tema em relação à alimentação com frutas.

C2: Está em pé, frente a uma mesa que tem uma prancha com miniaturas de frutas (maçá, banana, uva). Para cada fruta, há uma imagem ao lado fixada por meio de velcro. A criança observa as imagens e retira a figura da maçã.

FO: Após a criança C2 pegar a imagem da maçâ, a Fono retira a miniatura da maçã e mostra para C2.

C2: A criança pega a maçã e a explora. A criança deixa a imagem na mesa.

FO: É a figura da maçã. Olha só se náo é parecida. Aqui você tem a maçã pequena (indicando na máo de C2) e pega a figura e diz: e aqui é a imagem da maçá.

C2: Olha para a figura da maçã e continua a explorar o objeto maçã e emite: "da du tcha".

P: Essa é a maçá. Aqui tem a massinha que fizemos uma maçá. Olha vou tirar um pedaço para fazer de novo. Logo em seguida, $P$ indica a figura da maçã e diz: essa é a figura da maçã e na sua mão é uma maçã. Eu gosto de comer maçáa! 
O Exemplo 4 descreve o apoio dos objetos e das imagens na atividade a respeito da alimentação: relato de experiência da rotina alimentar. Importante destacar a relevância da mediação do fonoaudiólogo e da pesquisadora para a inserção dos recursos na atividade programada. Esse exemplo está de acordo com a discussão realizada por Light e McNaughton (2015), os quais apontam que as pesquisas devem ampliar o uso de recursos para a comunicação e a interação, mas os parceiros de comunicação precisam estar envolvidos e capacitados para a mediação e a elaboração de estratégias, para desenvolver a competência das crianças com TEA que não desenvolveram a comunicação oral e precisam ter acesso à informação e às experiências do idioma de sua comunidade linguística (Solomon-Rice \& Soto, 2011).

A mediação do adulto por meio do uso de sistemas suplementares e alternativos de comunicação pode favorecer a aquisição de vocabulário das crianças com TEA, além de favorecer o desenvolvimento de interação e comunicação (Nunes \& Walter, 2017). A seguir, serão apresentadas e discutidas as categorias em relação à habilidade de expressão das crianças participantes nas atividades realizadas.

\subsection{HABILIDADES DE EXPRESSÃo}

A identificação das diferentes habilidades de expressão em uma criança com TEA não é uma tarefa fácil, principalmente quando se tem como referência a aquisição e o desenvolvimento da fala. $\mathrm{O}$ uso da fala deve ser observado e cuidado, mas há necessidade de um olhar para as demais possibilidades expressivas de uma criança. A criança com TEA pode expressar uma vontade, um desejo e até um questionamento por diferentes habilidades. Cabe ao interlocutor ampliar suas competências e tornar-se um parceiro de comunicação na rotina de vida de toda criança.

No decorrer dos exemplos das categorias estabelecidas e definidas para este estudo, será possível perceber a importância do uso da mediação do parceiro de comunicação por meio de recursos e estratégias no momento de interação, para possibilitar o uso das diferentes habilidades comunicativas.

\subsubsection{EXPRESSÃo VERBAL E VOCAL}

O uso da fala de uma criança com TEA pode ser observado por diferentes elementos do sistema linguístico. A experiência com o idioma de uma comunidade demanda não só a recepção auditiva e o entendimento do que foi recebido, mas o seu uso. Dessa forma, cada emissão oral, mesmo sendo somente a emissão de fonemas (sons) ou apenas sílabas, pode exercer uma determinada função na situação de interação - pode, assim, ter um significado por meio da mediação do interlocutor. O Exemplo 5 ilustra a emissão de uma vogal e, no Exemplo 6 , a criança tenta a produção de uma consoante. Em ambas as situações, houve o modelo do interlocutor, que foi um parceiro de mediação em relação ao contexto da atividade explorada.

Exemplo 5: participantes: pesquisadora: P e a criança 1: C1. Atividade: história dos três porquinhos: colagem dos personagens da história dos três porquinhos:

C1: Puxa a mesa para mais próximo dele.

P: Você está arrumando a mesa, é?

C1: Entrega a cola que está em sua máo para P produzindo um som com entonaçáo: iiiii. 
P: Para mim? P pega a cola e diz: obrigada, você náo vai usar mais?

$\mathrm{C} 1$ : Olha para o porquinho de EVA que está em cima da mesa. Faz movimentos com a mão.

Pesquisadores da área da linguagem e comunicação alertaram os profissionais e os demais pesquisadores que seria importante valorizar os precursores de um sistema linguístico mais complexo; assim, o uso da entonação no momento da emissão da vogal pode oferecer à intencionalidade do emissor um valor maior ao seu significado (Sevcik et al., 2009). A criança C1 já havia finalizado o uso da cola e alertou o interlocutor a respeito da sua ação. Ao entregar a cola, já poderia ter finalizado sua intenção do final da sua tarefa, mas utilizou a produção de um fonema com entonação para o contato com o parceiro de comunicação na atividade.

$\mathrm{O}$ uso da fala e da escrita estão imersas nas atividades de narração de história. Cabe aos interlocutores, família, escola e demais profissionais, mediar as possibilidades dessa atividade de forma prazerosa. No Exemplo 6, a P. aproveita uma situaçáo já oferecida na escola para alertar a respeito da escrita e da produçáo do som do idioma durante o relato de vida.

Exemplo 6: participantes: pesquisadora: P e a criança 2: C2. Atividade: fotos da família e cartão com o nome da criança C2 para o trabalho de história de vida da criança.

P: Pega o nome escrito de $\mathrm{C} 2$ e diz: e aqui é o seu nome, igual você está aprendendo lá na sua escola.

C2: Olha para o nome e segura em sua mão.

P: Passa o dedo no nome escrito e diz para C2: Essa é a letra P que você já aprendeu lá na sua escola, P, P, P, P.

C2: Produz um som próximo do som da letra $P$.

P: P, P, P? Isso!!! Muito bem!!!

C2: Em seguida, não consegue a mesma produção.

O relato de experiência pessoal é descrito na literatura como a primeira etapa no desenvolvimento do discurso narrativo das crianças (Perroni, 1992). É uma etapa fundamental para a criança com TEA experienciar seu idioma e o vocabulário da sua rotina familiar e escolar, bem como estender o uso desses vocabulários em atividades programadas, como nos programas de intervenção na área da Saúde (Deliberato \& Ferreira-Donati, 2020; Smith, 2015).

$\mathrm{O}$ interlocutor precisa estar atento em como oferecer o modelo de vocabulário e demais elementos do sistema linguístico de um idioma. A área da Comunicação Suplementar e Alternativa tem sido um instrumento facilitador para as crianças com TEA, não só como habilidade de expressão, mas como um recurso de recepção do conteúdo e organização dos elementos necessários para a transmissão da mensagem.

Identificar a complexidade de habilidades de crianças com TEA e necessidades complexas de comunicação tem sido um desafio. Crianças com TEA podem apropriar-se de habilidades não verbais, quer vocal ou não vocal, com intencionalidade. Essas modalidades podem exercer funçóes fundamentais no processo de interação e comunicação, como discutido a seguir. 


\subsubsection{EXPRESSÃO NÁO VERBAL E VOCAL}

O Exemplo 7 apresenta uma situação lúdica entre a pesquisadora, a fonoaudióloga e a criança $\mathrm{C} 1$, por meio de atividade que envolvia a história adaptada do filme "Carros". De acordo com a mãe, a criança gosta muito desse filme e o assiste com muita frequência.

A narração de histórias envolve a criança com TEA no uso de sistemas suplementares e alternativos de comunicação. É uma possibilidade de ampliar o uso do sistema linguístico quando a fala não desenvolve, ou a fala desenvolve, mas não de forma suficiente para a comunicação efetiva. Há poucos estudos em relação à aquisição e ao desenvolvimento da narrativa com crianças com TEA não falantes, embora a literatura tenha ampliado a discussão a respeito das histórias sociais (Gray \& Garand, 1993).

As crianças com TEA podem usar a entonação da produção de som e ser compreendido no contexto da atividade e, principalmente, por interlocutores da sua rotina. Essa situação pode ser observada no Exemplo 7, na história "carros" com a C1 e sua mãe como interlocutora.

Exemplo 7: participantes: pesquisadora: P, fonoaudiólogo: FO, mãe: M1 e a criança 1: C1. Atividade: história dos carros: uso de objetos e imagens pictográficas.

C1: Vai em direção à M1 levando o carro desmontado e produzindo um som com entonaçáo (como se estivesse reclamando).

FO: O que aconteceu?

C1: Tenta encaixar as partes do carro e produz um som com a boca ao mesmo tempo.

FO: Quebrou?

P: A agente arruma, a mamáe ajuda.

C1: Entrega o carro na máo da máe.

M1: Deixa eu ver entáo? você quer que arrume?

P: Produz um som sem uma articulaçáo definida com entonaçáo olhando para o carro posicionado à frente da máe.

M1: Entáo vamos arrumar. M1 tenta encaixar o carro e diz: só que quebrou um pedaço.

O uso da prosódia do idioma é outro elemento importante e pode ser uma habilidade usada pela criança com TEA no momento da comunicação, como foi possível observar no diálogo entre C1 e sua mãe. Contudo, é importante destacar que, além do modelo de fala oferecido pela mãe, demonstrando seu entendimento frente à produção vocal do seu filho, há a necessidade do uso de apoio de sistemas de representação a sua intencionalidade, como, no caso, o uso dos sistemas suplementares e alternativos de comunicação.

Assim sendo, a literatura discute a necessidade de criar situaçóes para que as crianças com TEA possam usar suas habilidades iniciais de comunicação, mas é preciso inserir no contexto sistemas de representação para que essas crianças possam ampliar a construção e a emissão dos seus desejos e de suas intençôes. Segundo os estudos de Von Tetzchner et al. (2005), a Educação Infantil é um ambiente propicio para a aquisição e o desenvolvimento das linguagens alternativas.

Outra habilidade observada com frequência nas crianças com TEA é o choro como uma possibilidade de transmitir uma intenção, como pode ser observado no Exemplo 8, com a C2. 
Exemplo 8: participantes: pesquisadora: P e a criança 2: C2. Atividade: fotos da família e cartão com o nome da criança C2 para o trabalho de história de vida da criança.

P: Dá para a gente brincar aqui (apontando a porta de EVA), dá para a gente brincar juntos. Assim ó. Desgruda a porta de EVA da placa. Olha P2, desgruda.

C2: Faz um som com a boca (como o de um caminháo) e segurou a porta.

P: Colocou o rosto na porta de EVA aberta e falou: eeei....oie.......

C2: Se estica e faz uma expressáo de choro. Em seguida, começa a chorar colocando as pernas na mesa.

P: Não? Assim não?

C2: Grita e chora movimentando as pernas.

P: Nossa! Que bravo. Que bravo que você está hoje.

O choro e demais comportamentos inadequados usados com o corpo, como no Exemplo 8, pode indicar ou expressar um determinado comportamento, como, no caso, bravo, mas também poderia indicar que a criança $\mathrm{C} 2$ não gostou da tarefa estabelecida. $\mathrm{O}$ choro e demais comportamentos devem ser registrados e observados em conjunto à família e escola para que possam ser trabalhados e adequados à forma de expressão.

\subsubsection{EXPRESSÃo NÁO VERBAL E NÁO VOCAL}

Outras formas de uso do corpo, como gestos e expressóes faciais no contexto da atividade da história, podem ser utilizadas pelas crianças com TEA, a fim de facilitar a interação, como pode ser observado no Exemplo 9 com a C2.

Exemplo 9: Pesquisadora: P e a Terapeuta ocupacional: TO e a criança C2. Atividade: uso dos personagens peixes (objetos), modelagem com massa e correspondência das imagens.

P: Vamos brincar de massinha! P. entrega o cartão para TO e diz: toma TO, vamos brincar de massinha.

TO: Olha para C2 e diz: dá um pedacinho para mim (estica o braço e retira um pedaço de massinha de C2).

C2: Pega a massinha de volta e faz uma expressáo facial de choro, uma careta, com uma tentativa de emissáo choro, mas sem som.

P: Ah! Você não quer separar nada da massinha.

As crianças com TEA com necessidades complexas de comunicação acabam buscando habilidades expressivas que sejam mais funcionais no seu ambiente natural, principalmente no contexto familiar. Algumas das habilidades, como ilustrada no Exemplo 9, favoreceram a fluência da interaçáo comunicativa e podem ser mediadas pelo discurso oral e por meio dos sistemas suplementares e alternativos de comunicação. $\mathrm{O}$ exemplo reforça que a narração de histórias pode ser um instrumento que insere a criança com TEA na situaçáo dialógica, mesmo que com uso de habilidades precursoras ao discurso mais complexo (Solomon-Rice \& Soto, 2011), possibilitando a combinação de modalidades expressivas, como descritas a seguir. 


\subsubsection{EXPRESSÓES COMBINADAS}

A intencionalidade de uma mensagem pode estar vinculada à combinação das habilidades expressivas de uma criança com TEA. Tal habilidade pode ser observada no exemplo 10.

Exemplo 10: participantes: Pesquisadora: P e a criança C2. Atividade: uso de fotos da família para o trabalho do relato de vida da criança.

C2: Pega a foto e tira do velcro.

P: Achou! É a mamãe e o R...e você (apontou a foto dele). Só está faltando o papai.

C2: Ficou olhando a foto.

P: É para a gente contar a sua história.

C2: Segura a foto da máe e do irmáo, olha para a foto e abre e fecha o olho.

P: É a mamáe, seu irmáo e você (apontando as fotos).

C2: Pega a foto dele e diz 'ti cá pa pá in qui tu'.

O Exemplo 10 ilustra o uso de sistemas suplementares e alternativos de comunicação, uso de expressão facial e emissão de sílabas. $\mathrm{O}$ uso das imagens pode ser um facilitador para a emissão verbal e oral. A literatura tem alertado a necessidade do uso precoce do conhecimento da área da Comunicação Suplementar e Alternativa na rotina das crianças com TEA, não só em função das novas tecnologias para usar na rotina, mas em função de como os sistemas pictográficos podem mediar a construção da linguagem (Deliberato \& Nunes, 2015).

\section{Conclusāo}

Este estudo descreveu a mediação do adulto e as habilidades comunicativas de duas crianças com TEA em situaçóes lúdicas, por meio da narração de histórias. Embora a literatura a respeito da aquisição e o desenvolvimento da narrativa em crianças com TEA seja escassa, esta pesquisa mostrou que o uso da narração pode ser um caminho importante para as crianças com TEA no que diz respeito à interação e à comunicação. A narração de histórias foi um instrumento importante para a mediação dos interlocutores com as crianças e de suas estratégias para favorecer a participação das crianças durante a atividade, além de favorecer a ampliação das habilidades de comunicação durante o programa realizado. As famílias e os professores foram orientados em relação às atividades, aos recursos e às estratégias que poderiam ser realizadas em continuidade ao programa.

Destaca-se também, neste estudo, a intervenção clínica em uma perspectiva colaborativa, envolvendo família e escola. As discussóes a respeito da narração de histórias e das histórias sociais para as crianças com TEA devem ser sistematizadas na rotina escolar, principalmente na Educação Infantil, com parceria com a área da Saúde.

É importante ressaltar que a proposta de intervenção colaborativa considerou o conhecimento teórico e prático de profissionais de diferentes áreas, como no caso a fonoaudiologia, a psicologia e a terapia ocupacional, por meio de parcerias, promovendo açóes a fim de ampliar as habilidades comunicativas da criança com TEA. Os resultados dessa proposta reforçam a importância do trabalho entre diferentes áreas de conhecimento, a fim de promover estratégias para o desenvolvimento de competências das crianças com TEA. 
A pesquisa apresentou limitações com relação ao número de participantes. Sugeremse novos estudos com uma maior quantidade de crianças com TEA em idades variadas e contextos distintos. Além disso, ressalta-se a importância de novas pesquisas darem destaque aos recursos e às estratégias utilizados em parcerias colaborativas.

\section{REFERÊNCIAS}

Binger, C., \& Light, J. (2007). The effect of aided AAC modeling on the expression of multi-symbol messages by preschoolers who use AAC. Augmentative and alternative communication, 23(1), 30-43.

Campelo, L. D., Lucena, J. A., Lima, C. N. de, Araújo, H. M. M. de, Viana, L. G. de O., Veloso, M. M. L., Correia, P. I. F. de B., \& Muniz, L. F. (2009). Autismo: um estudo de habilidades comunicativas em crianças. Rev. CEFAC, 11(4), 598-606. https://doi.org/10.1590/S1516-18462009000800008

Campos, K. C. (2016). Nossas vidas contam histórias: Crianças narradoras. [Tese de Doutorado, Centro de Ciências da Educação, Universidade Federal de Santa Catarina]. Repositório UFSC. https:// repositorio.ufsc.br/handle/123456789/175896

Carvalho, A. M. P. (1996). O uso do vídeo na tomada de dados: pesquisando o desenvolvimento do ensino em sala de aula. Pro-posiçôes, 7(1), 5-13.

Cruz, S. G., Oliveira, T. A., \& Fantacini, R. A. F. (2017). A indissociabilidade do brincar, cuidar e educar na Educação Infantil. Research, Society and Development, 4(4), 227-238.

Delagracia, J. D., Manzini, E. J., \& Deliberato, D. (2015) Protocolo para identificação de habilidades comunicativas no contexto familiar. In D. Deliberato, \& E. J. Manzini (Orgs.), Instrumentos para avaliação de alunos com deficiência sem oralidade (pp. 63-83). M\&M Editora.

Deliberato, D. (2013). Comunicação alternativa na escola: possibilidades para o ensino do aluno com deficiência. In A. P. Zaboroski, \& J. P. Oliveira (Orgs.), Atuação da Fonoaudiologia na escola: reflexóes e práticas (pp. 71-90). WAK Editora.

Deliberato, D., \& Adurens, F. D. L. (2019). Tecnologia assistiva: comunicaçáo alternativa no conto e reconto de história na escola. In W. D. Guilherme (Org.), Educação Inclusiva e Contexto Social: Questôes Contemporâneas (pp. 249-259). Atena Editora.

Deliberato, D., \& Ferreira-Donati, G. C. (2020). Narração de histórias: recursos e estratégias com a comunicação alternativa. In: C. A. S. Azoni, \& J. O. Lira (Orgs.), Estratégias e orientaçôes em linguagem: um guia em tempos de COVID 19 [recurso eletrônico] (pp. 88-99). Sociedade Brasileira de Fonoaudiologia.

Deliberato, D., \& Nunes, L. R. O. P. (2015). Use of graphic systems in the routine of a regular classroom with a disabled student. Education Policy Analysis Archives, 23(34), 1-26.

Fagundes, A. J. F. M. (1999). Descrição, definição e registro do comportamento. Edicon,

Fiorini, B. S. (2017). O aluno com transtorno do espectro do autismo na educação infantil: caracterização da rotina escolar. [Dissertaçáo de Mestrado, Faculdade de Filosofia e Ciências da Universidade Estadual Paulista]. Repositório UNESP. https://repositorio.unesp.br/handle/11449/150463

Fonseca, C. (1999). Quando cada caso NÃO é um caso de pesquisa etnográfica e educação. Revista Brasileira de Educação, 10, 58-78.

Gray, C. A., \& Garand, J. D. (1993). Social stories: Improving responses of students with autism with accurate social information. Focus on Autistic Behavior, 8(1), 1-10. 
Hayward, D., \& Scheneider, P. (2000) Effectiveness of teaching story grammar knowledge to pre-school children with language impairment. An exploratory study. Child Language Teaching and Therapy, 16(3), 255-284.

Light, J., \& Mcnaughton, D. (2015). Designing AAC research and intervention to improve outcomes for individuals with complex communication needs. Augmentative and Alternative Communication, 31(2), 85-96.

Light, J., Mcnaughton, D., \& Caron, J. (2019). New and emerging AAC technology supports for children with complex communication needs and their communication partners: State of the science and future research directions. Augmentative and Alternative Communication, 35(1), 26-41.

Martins, A. D. F., \& Góes, M. C. R. (2013) Um estudo sobre o brincar de crianças autistas na perspectiva histórico-cultural. Psicologia Escolar e Educacional, 17(1), 25-34.

Mattos, L. K. de, \& Nuernberg, A. H. (2011). Reflexôes sobre a inclusão escolar de uma criança com diagnósticos de autismo na Educação Infantil. Revista Educação Especial, 24(39), 129-141.

Mcgregor, K. K. (2000). The development and enhancement of narrative skills in preschool classroom: Towards a solution to clinician-client mismatch. American Journal of Speech-Language Pathology, $9(1), 55-71$.

Mcnaughton, D., Light, J., Beukelman, D. R., Klein, C., Nieder D., \& Nazareth, G. (2019). Building capacity in AAC: A person-centred approach to supporting participation by people with complex communication needs. Augmentative and Alternative Communication, 35(1), 56-68.

Mendes, E. G., Almeida, M. A., \& Toyoda, C. Y. (2011). Inclusão escolar pela via da colaboração entre educação especial e educaçáo regular. Educar em Revista, 41, 80-93.

Menezes, L. C., \& Amorim, K. S. (2015). Para além dos déficits: interação e atenção conjunta em crianças com autismo. Psicologia em Estudo, 20(3), 353-364. https://doi.org/10.4025/psicolestud. v20i3.27141

Millikin, C. C. (1997) Symbol systems and vocabulary selection strategies. In S. L. Glennen, \& D. C DeCoste. Handbook of Augmentative and Alternative Communication (pp. 97-148). Singular Publishing Group.

Nunes, D. R. P., \& Walter, C. C. F. (2017). Análise da produção nacional sobre autismo e comunicação. In D. Deliberato, D. Nunes, \& M. Gonçalves. (Orgs.), Trilhando juntos a Comunicação Alternativa (pp. 385-400). ABPEE.

Oliveira, S. A., \& Scherer Júnior, A. (2019). A contação de histórias no ensino fundamental: fundamentos e planejamentos. Cadernos de Pedagogia, 13(25), 16-26.

Paula, R., Manzini, E. J., \& Deliberato, D. (2015) Protocolo para identificação de habilidades comunicativas no contexto escolar. In D. Deliberato, \& E. J. Manzini (Orgs.), Instrumentos para avaliação de alunos com deficiência sem oralidade (pp. 41-62). M\&M Editora.

Perroni, M. C. (1992). O desenvolvimento do discurso narrativo. Martins Fontes.

Ponsoni, A. (2010). Comunicação suplementar e alternativa no discurso narrativo do aluno com paralisia cerebral. [Dissertação de Mestrado, Faculdade de Filosofia e Ciências, Universidade Estadual Paulista]. Repositório UNESP. https://repositorio.unesp.br/handle/11449/91188

Rocha, A. N. D. C. (2013). Recursos e estratégias da Tecnologia Assistiva a partir do ensino colaborativo entre os profissionais da saúde e da educação. [Tese de Doutorado, Faculdade de Filosofia e 
Ciências, Universidade Estadual Paulista]. Repositório UNESP https://repositorio.unesp.br/ handle/11449/102193

Scalha, T. B., Souza, V. G., Boffi, T., \& Carvalho, A. C. (2010). A importância do brincar no desenvolvimento psicomotor: relato de experiência. Revista de Psicologia da Unesp, 9(2), 79-92.

Sevcik, R., Romski, M. A., \& Wilkinson, K. (2009). Roles of graphic symbols in the language acquisition process for persons with severe cognitive disabilities. Augmentative and alternative communication, 7(3), 161-170.

Smith, M. M. (2015). Language development of Individuals who require aided communication: reflections on state of the science and future research directions. Augmmentative Alternative Communication, 31(3), 215-233.

Solomon-Rice, P., \& Soto, G. (2011). Co-Construction as a facilitative factor in supporting the personal narratives of children who use Augmentative and Alternative Communication. Communication Disorders Quarterly, 32(2), 70-82.

Tomasello, M. (2003). Constructing a language: A usage based theory of language acquisition. Harvard University Press.

Trivellato-Ferreira, M. C., Ferreira, A. T., \& Marturano, E. M. (2016). Socialização em creche: um estudo sobre comportamento e brincadeiras de crianças pequenas. Revista Psicologia: Teoria e Prática, 18(3), 127-140.

Vitta, F. C. F., Corrêa, A. Q., Medeiros, M. F., Novaes, C. F. M., \& Mouro, M. M. (2017). O brincar de 0 a 2 anos no contexto da educação infantil. In J. P. Oliveira, A. N. D. C. Rocha, R. K. K. Miura, \& E. S. Rodrigues (Orgs.), Desenvolvimento infantil, escola e inclusão: açôes pedagógicas e intersetoriais (pp. 95-118). CRV.

Von Tetzchner, S. (2015). The semiotics of aided language development. Cognitive Development, 36, 180-190.

Von Tetzchner, S. (2018) Introduction to the special issue on aided language processes, development, and use: An international perspective. Augmentative and Alternative Communication, 34(1), 1-15.

Von Tetzchner, S., Brekke, K. M., Sjothun, B., \& Grindheim, E. (2005). Inclusão de crianças em educação pré-escolar regular utilizando comunicação suplementar e alternativa. Revista Brasileira de Educação Especial, 11(2), 151-184.

Recebido em: 01/07/2020

Reformulado em: 10/09/2020

Aprovado em: 17/10/2020 